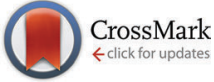

Cite this: New J. Chem., 2015, 39, 2060

Received (in Montpellier, France) 21st October 2014

Accepted 6th January 2015

DOI: 10.1039/c4nj01855a

www.rsc.org/njc

\section{Tolane-based bent bolaamphiphiles forming liquid crystalline hexagonal honeycombs with trigonal symmetry $\dagger$}

\author{
Hongfei Gao, $\ddagger^{\mathrm{a}}$ Huifang Cheng, $\ddagger^{\mathrm{a}}$ Qijing Liu, ${ }^{\mathrm{a}}$ Yulong Xiao, ${ }^{\mathrm{a}}$ Marko Prehm, ${ }^{\mathrm{b}}$ \\ Xiaohong Cheng ${ }^{{ }^{a}}$ and Carsten Tschierske ${ }^{\star b}$
}

Bolaamphiphiles consisting of a bent 1,3-bis(phenylethynyl)benzene core with two terminal glycerol units, a lateral $n$-alkyl chain in the bay-position and a methyl group at the apex of the central 1,3-substituted benzene ring have been synthesized via Sonogashira coupling reactions as key steps. The thermotropic and solvent-modified or solvent-induced liquid crystalline (LC) phases of these compounds were investigated by POM, DSC and X-ray scattering. Compounds with medium alkyl chain length form a hexagonal honeycomb LC phase with non-centrosymmetric trigonal $p 3 m 1$ symmetry as a monotropic LC phase. The addition of water increases the LC phase range, leading to enantiotropic $p 3 \mathrm{~m} 1$ phases and induces LC phases for the non-mesomorphic compounds with shorter and longer lateral alkyl chains.

\section{Introduction}

The design of new functional molecules which can selforganize into well defined two-dimensional (2D) arrays with potential nanotechnological applications is of current interest. Especially, liquid crystals (LCs) ${ }^{1}$ represent soft self-assembled materials with significant technological importance ${ }^{1,2}$ and provide routes to increased complexity in soft self-assembly. ${ }^{3}$ Among them, a series of polygonal honeycomb LCs were created by the self-assembly of T-shaped and X-shaped bolaamphiphiles composed of a rod-like core, two polar end groups and one (T-shaped) $)^{4,5}$ or two (X-shaped) laterally attached lipophilic or fluorophilic chains. ${ }^{6,7}$ In these molecules strongly incompatible building blocks are combined in a competitive manner which leads to new LC phases with enhanced complexity compared to the usually observed nematic, smectic and columnar LC phases. ${ }^{1}$ By combination of different lipophilic and fluorophilic lateral chains new modes of molecular self-assembly could be achieved, providing multicompartment LC phases. ${ }^{8,9}$ Bentshaped molecules composed of a non-linear, approximately $120^{\circ}$ bent rigid core with terminal alkyl chains have also attracted

\footnotetext{
${ }^{a}$ Key Laboratory of Medicinal Chemistry for Natural Resources, Chemistry Department, Yunnan University, Kunming, Yunnan 650091, P. R. China. E-mail: xhcheng@ynu.edu.cn; Fax: +868715032905

${ }^{b}$ Institute of Chemistry, Organic Chemistry, Martin-Luther University Halle-Wittenberg, Kurt-Mothes Str. 2, 06120 Halle/Saale, Germany.

E-mail: carsten.tschierske@chemie.uni-halle.de; Fax: +49 3455527346

$\dagger$ Electronic supplementary information (ESI) available. See DOI: 10.1039/ c4nj01855a

$\ddagger$ Both authors contributed equally to this work.
}

significant interest in the recent years, because such achiral molecules can organize into chiral superstructures and into polar lamellar and columnar LC phases with ferroelectric and antiferroelectric properties (Scheme 1a). ${ }^{10}$ Adding a lateral alkyl chain into the bay position of these bent-core mesogens removes polar order in the LC phases. ${ }^{11}$ On the other hand, introducing a chain which is incompatible with the terminal chains or groups into the bay position of the bent core, as for example by combination of polar end groups with a lipophilic lateral alkyl chain, leads to the formation of hexagonal columnar phases representing hexagonal honeycombs (Scheme $1 \mathrm{~b}$ and c). ${ }^{12}$ Two different types of hexagonal honeycombs were obtained, depending on the ratio of the bent core size and lateral chain length, those with six molecules in the circumference of the honeycomb cells, having a relatively large hexagonal lattice parameter and hexagonal $p 6 \mathrm{~mm}$ symmetry $\left(\mathrm{Col}_{\text {hex-6 }} / \mathrm{p} 6 \mathrm{~mm}\right.$, Scheme 1c) and those with only three molecules in the periphery, having much smaller lattice parameters and a non-centrosymmetric trigonal $p 3 m 1$ symmetry $\left(\mathrm{Col}_{\text {hex- } 3} / p 3 m 1\right.$, Scheme 1b). ${ }^{10}$ Non-centrosymmetric soft matter structures are of significant interest, as for example, for use in NLO applications. ${ }^{13,14}$ In order to obtain significant NLO activity a strong molecular dipole moment is required, which can be achieved by introduction of appropriate substituents at the apex of the $\pi$-conjugated bent core. Therefore, the investigation of the general effects of such additional substituents on mesomorphic selfassembly, and specifically on the ability of these bent-core bolaamphiphiles to form hexagonal honeycombs with trigonal symmetry, is of interest.

In the first step, to evaluate the influence of steric effects, we report herein the effect of an additional methyl group. 

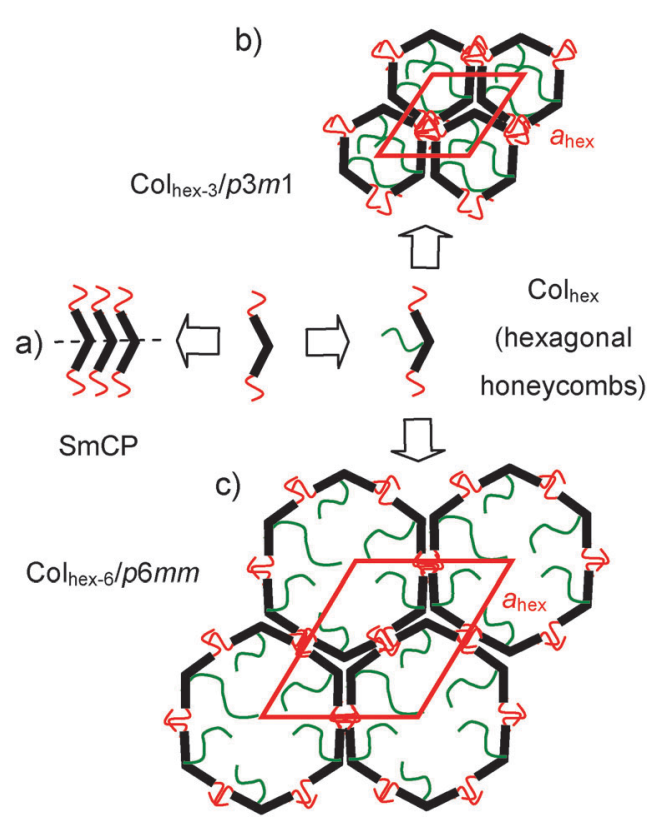

Scheme 1 Principal modes of LC self-assembly of bent-core mesogens with or without a chain in the bay position; SmCP = tilted polar smectic phase, $\mathrm{Col}_{\text {hex }}=$ hexagonal columnar phase; the Colnex phases have a honeycomb structure and are shown as cross sections through these honeycombs perpendicular to the column long axis; $C_{\text {hex }-3}$ phases have 3 molecules in the circumference of each honeycomb cell, providing $p 3 m 1$ symmetry and $\mathrm{Col}_{\text {hex- }} 6$ phases have 6 molecules in the circumference of each honeycomb cell, providing $p 6 \mathrm{~mm}$ symmetry.

This group was introduced at the apex of the bent core (in position 5 of the central 1,3-disubstituted benzene ring) in molecules $\mathbf{1} / \boldsymbol{n}$ consisting of a $\pi$-conjugated 1,3-bis(phenylethynyl)benzene bent-core, two terminal glycerol units and having a long lateral alkyl chain of variable length $n$ in the 2-position (bay position) at the central benzene ring (see Scheme 2). Specifically, the influence of the length of the lateral chain and the effect of water as a polar solvent on LC self-assembly were investigated.

\section{Results and discussion}

\subsection{Synthesis}

The bent-core bolaamphiphiles $\mathbf{1} / \boldsymbol{n}$ have been synthesized via Sonogashira coupling reactions as key steps, as shown in Scheme 3. Accordingly, 2,6-diiodo-4-methylphenol 2, obtained by iodination of $p$-cresol, ${ }^{15}$ was alkylated with appropriate $n$-alkyl bromides ${ }^{16}$ and then coupled with 1,2-O-isopropylidene glycerol substituted<smiles>[R]Oc1c(C#Cc2ccc(OCC(O)CO)cc2)cc(C)cc1C#Cc1ccc(OCC(O)CO)cc1</smiles>

Scheme 2 Structure of compounds $1 / n$ under investigation.

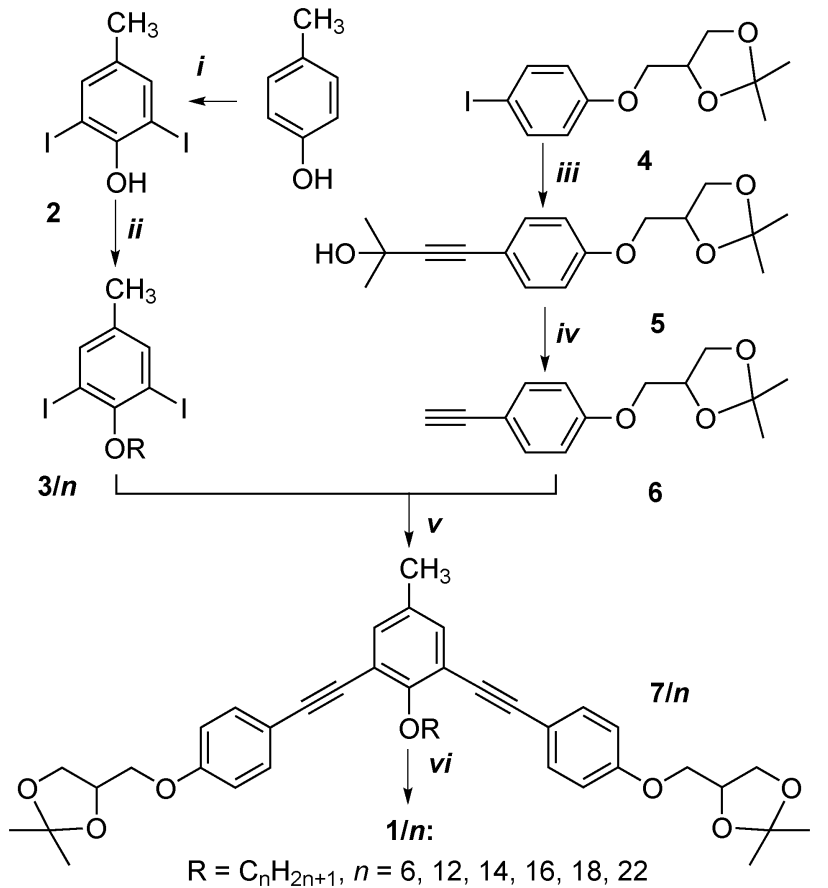

Scheme 3 Synthesis of bent shaped bolaamphiphilies $1 / n$; Reagents and conditions: (i) $\mathrm{I}_{2}, \mathrm{Kl}$, ammonia, $\mathrm{MeOH}, 25{ }^{\circ} \mathrm{C}, 2 \mathrm{~h}, 52 \%$; (ii) $\mathrm{C}_{n} \mathrm{H}_{2 n+1} \mathrm{Br}, \mathrm{K}_{2} \mathrm{CO}_{3}$, DMF, $95^{\circ} \mathrm{C}, 20$ h, 75-86\%; (iii) 2-methylbut-3-yn-2-ol, THF, Et 3 N, $\mathrm{Pd}\left(\mathrm{PPh}_{3}\right)_{4}$, Cul, $25{ }^{\circ} \mathrm{C} 89 \%$; (iv) $\mathrm{KOH}$, toluene, reflux, $15 \mathrm{~h}, 88 \%$; (v) THF, $\mathrm{Et}_{3} \mathrm{~N}, \mathrm{Pd}\left(\mathrm{PPh}_{3}\right)_{4}$, Cul, $25{ }^{\circ} \mathrm{C}$ 64-88\%; (vi) PPTS, $\mathrm{CH}_{3} \mathrm{OH}, 25^{\circ} \mathrm{C}, 15 \mathrm{~h}, 77-87 \%$.

phenylacetylene $6^{17}$ in a Sonogashira coupling reaction, ${ }^{18}$ leading to the 1,2-O-isopropylidene glycerol substituted 1,3-bis(phenylethynyl)benzenes $7 / \boldsymbol{n}$. In the last step the 1,2-O-isopropylidene groups were cleaved with pyridinium $p$-toluenesulfonate (PPTS) in $\mathrm{CH}_{3} \mathrm{OH} .{ }^{12,19}$ The final compounds $\mathbf{1} / \boldsymbol{n}$ were purified by repeated crystallization from petroleum ether/ethyl acetate mixtures $(1: 2)$. The detailed procedures and corresponding analysis data are collected and given in the ESI. $\dagger$

\subsection{Mesomorphic properties}

The LC self-assembly of compounds $\mathbf{1} / \boldsymbol{n}$ was investigated by polarized optical microscopy (POM), differential scanning calorimetry (DSC), and X-ray diffraction (XRD). The phase transition temperatures and the corresponding enthalpy values of the newly synthesized compounds $\mathbf{1} / \boldsymbol{n}$ together with the previously reported compound $\mathbf{2 / 1 2}$ without the 5-methyl group and a lateral $\mathrm{C}_{12} \mathrm{H}_{25}$ alkyl chain ${ }^{12}$ are collated in Table 1. Monotropic (metastable) LC phases were observed only for compounds 1/14 and 1/16 with a medium length of the alkyl chain in the bay position and the LC phases were lost by decreasing or increasing the alkyl chain length $n(n=6,12,18$, and 22).

The optical textures of the monotropic LC phases of compounds $\mathbf{1} / \mathbf{1 4}$ and 1/16, as obtained by cooling from the isotropic liquid and observed between crossed polarizers, are characterized by highly birefringent spherulitic domains coexisting with large homotropically aligned regions appearing completely dark and interrupted by filament-like defects (see Fig. 1a and c). 
Table 1 LC phase transitions and other parameters of compounds $1 / n^{a}$ compared with the previously reported compound $\mathbf{2 / 1 2} \mathbf{2}^{12}$ and the effect of water on mesophase stability

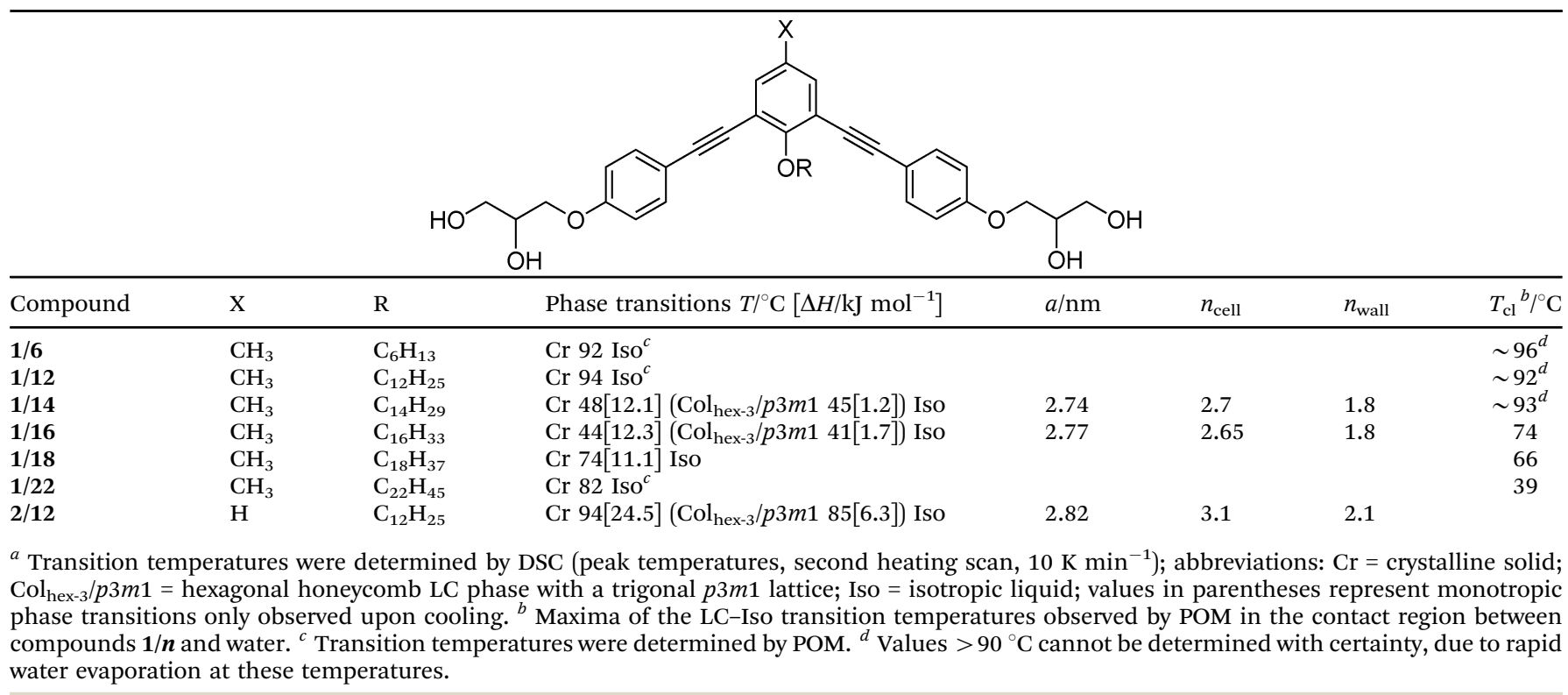

These textures indicate columnar LC phases which are optically uniaxial. As confirmed by investigations using a $\lambda$ retarder plate (see Fig. $1 \mathrm{~b}$ and $\mathrm{d}$ ) the birefringence of the LC phases is negative, i.e. the high index axis, which is known to be parallel to the long axis of the $\pi$-conjugated cores, is perpendicular to the column long axis. This means that the bent aromatic cores of compounds $\mathbf{1} / \boldsymbol{n}$ are aligned perpendicular to the column long axis in the plane of the $2 \mathrm{D}$ lattice and this is in line with a polygonal honeycomb structure of these LC phases with a uniaxial square or hexagonal lattice.

The XRD patterns of both compounds are characterized by a diffuse wide angle scattering at $d=0.44-0.45 \mathrm{~nm}$, confirming the presence of liquid like disorder and a series of sharper small angle scatterings, indicating the presence of a long range periodicity, as typically observed for LCs (Fig. 1e and f). There is one very strong and three weak small angle diffraction peaks with a ratio of their reciprocal spacings of $1: 2: 7^{1 / 2}: 12^{1 / 2}$ which can be indexed to the 10,20, 21 and 22 reflections of a hexagonal lattice. This indicates hexagonal columnar mesophases for compounds 1/14 and 1/16 (Fig. 1e and $\mathrm{f}$ and Table S1, ESI $\dagger$ ). The hexagonal lattice parameters $a_{\text {hex }}$ are 2.74 and $2.77 \mathrm{~nm}$ for compounds $\mathbf{1 / 1 4}$ and $\mathbf{1 / 1 6}$, respectively. This relatively small value of $a_{\text {hex }}$, compared to the molecular dimensions, confirms that both hexagonal columnar mesophases should be formed by 3-hexagons, leading to a trigonal columnar phase with $p 3 m 1$ symmetry ( $\mathrm{Col}_{\text {hex- } 3} / p 3 m 1$ phases). ${ }^{12}$ In this case the side length of the hexagons $\left(l_{\text {hex }}\right)$ is related to the hexagonal lattice parameter $\left(a_{\text {hex }}\right)$ through $l_{\text {hex }}=a_{\text {hex }} / 3^{1 / 2} \sim 1.6 \mathrm{~nm}$ and this value is in agreement with the length of each leg ( $L=1.5 \mathrm{~nm}$ ) of the 1,3-bis(phenylethynyl)benzene unit of the molecules $1 / \boldsymbol{n}$ as measured with molecular models between the middle of the 5-methylresorcinol core and the end of the primary $\mathrm{OH}$ group of the glycerol unit, assuming a most extended conformation. The hexagonal lattice parameters of 1/14 and $\mathbf{1} / \mathbf{1 6}$ are also very similar to that of the previously reported compound 2/12 ( $a_{\text {hex }}=2.82 \mathrm{~nm}$, see Table 1$)$ for which the trigonal symmetry was additionally confirmed by reconstruction of electron density maps. ${ }^{12}$ If there would be larger 6-hexagon cylinders, leading to a hexagonal $p 6 \mathrm{~mm}$ symmetry $\left(\mathrm{Col}_{\text {hex-6 }} / p 6 \mathrm{~mm}\right.$, Scheme 1), a lattice parameter $a_{\mathrm{hex}}$ around $4-5 \mathrm{~nm}$ would be expected. ${ }^{12}$ This means that in the $\mathrm{Col}_{\text {hex- } 3} / p 3 m 1$ phases of compounds $\mathbf{1 / 1 4}$ and $\mathbf{1 / 1 6}$ each side of the hexagon is made up of one arm of the bent molecules, as shown in Scheme $1 \mathrm{~b}$ and Fig. 19. In the honeycomb frames three molecules are organized in the circumference of each hexagonal cell with the bent aromatic cores arranged in the plane of the 2D-lattice and aligned perpendicular to the resulting channels, in line with the experimentally observed negative birefringence of these LC phases. In the resulting honeycomb walls two individual legs of adjacent bent shaped aromatic units are arranged parallel side-by-side. The dynamic hydrogen bonding networks between the glycerol end-groups fuse these walls to hexagonal honeycombs and the prismatic cells resulting inside these honeycombs are filled with the long alkyl chains in the 2-position. The nodes of the honeycomb are alternating, only three of them are formed by the hydrogen bonding networks of the glycerol groups and those between them are made up by the apexes of the bent-core units, thus leading to the reduced trigonal symmetry (plane group p3m1). According to the calculation in Table S2 (ESI $\dagger$ ), the number of molecules in each unit cell with an assumed height of $0.45 \mathrm{~nm}$ (the maximum of diffuse wide angle scattering) is about three $\left(n_{\text {cell }}=2.7-2.8\right)$, which is in line with the proposed mode of molecular organization (see Table 1 and Table S2, ESI $\dagger$ ). The slight deviation from being exactly three could be due to a deviation of the corecore distance along the columns from the assumed value of $0.45 \mathrm{~nm}$ and to a slight staggering of the aromatic cores along the honeycomb walls, as known for previously reported LC honeycombs. ${ }^{4-8}$ 


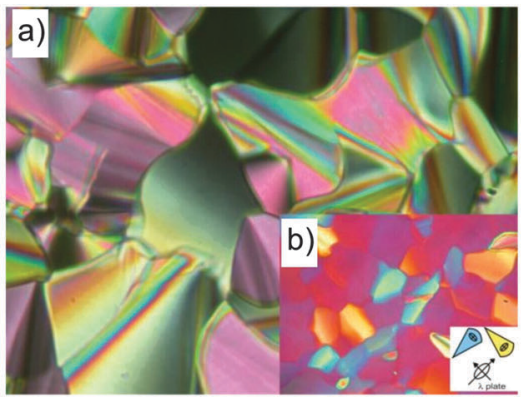

e)

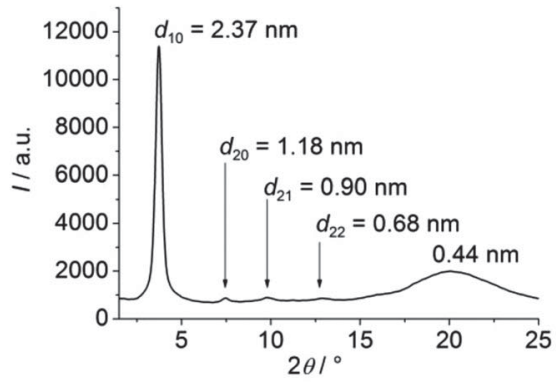

f)
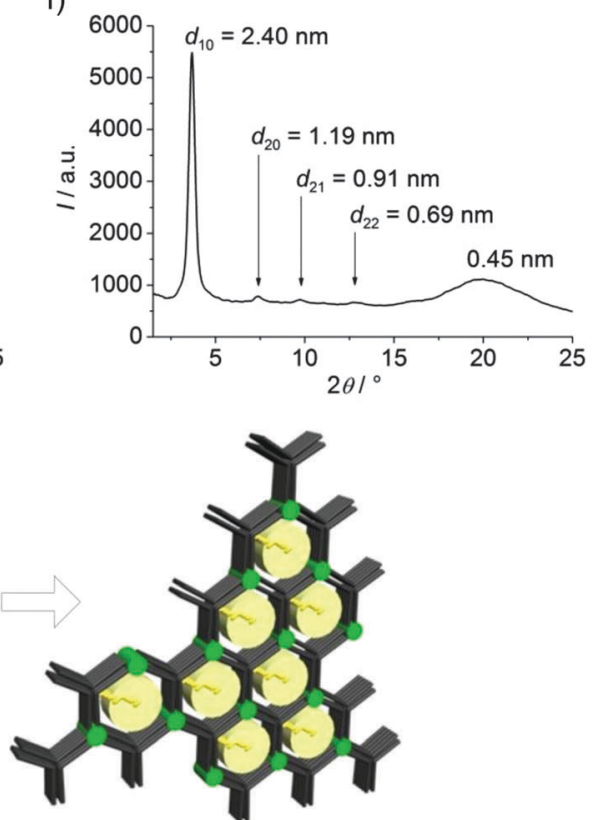

Fig. 1 Colnex-3/p3m1 phases of compounds $1 / 14$ and 1/16: (a) texture of $1 / 14$ as seen between crossed polarizers upon cooling from the isotropic state at $T=42^{\circ} \mathrm{C}$; (b) with additional $\lambda$-plate, the indicatrix orientation in the compensator is shown in the inset; (c) texture of $1 / 16$ at $T=42{ }^{\circ} \mathrm{C}$; (d) with $\lambda$-plate; (e) XRD pattern of $1 / 14$ at $T=35^{\circ} \mathrm{C}$; and (f) of $1 / 16$ at $T=35^{\circ} \mathrm{C}$; (g) models of molecular organization in the hexagonal honeycombs with $p 3 m 1$ lattices; the bent aromatic cores are shown in gray; green circles/columns represent the hydrogen bonding networks of the glycerol groups, the yellow region represents the honeycomb cells filled by the alkyl chains.

Compound $\mathbf{1} / \mathbf{1 2}$ has a higher melting point at $T=94{ }^{\circ} \mathrm{C}$, which can be supercooled to $T=41{ }^{\circ} \mathrm{C}$, when the compound slowly crystallizes without formation of any LC phase. Even at $T=30{ }^{\circ} \mathrm{C}$ no LC phase could be detected between the developing crystallites (see Fig. S1, ESI $\dagger$ ). Thus, comparison of compound 2/12 without the 5 -substituent and compound 1/12 with the 5 -methyl group (Table 1 ) indicates that the melting point is increased and the LC phase is strongly depressed or even completely removed by introduction of the 5-substituent. This clearly indicates a mesophase destabilizing effect of this substituent, which is easily explained by steric distortion of the molecular packing into a honeycomb structure due to packing frustration at the nodes formed by the methyl substituted molecular apexes. However, if the 2-alkyl chain is further elongated the melting points are significantly reduced and $\mathrm{Col}_{\text {hex-3 }} / \mathrm{p} 3 \mathrm{~m} 1$ phases can be observed for compounds $\mathbf{1} / \mathbf{1 4}$ and 1/16, though the mesophase stability, i.e. the LC-Iso phase transition temperature is significantly lower than that observed for compound 2/12 without the methyl group. This means that an increased alkyl chain length is required to obtain LC phases for the methyl substituted compounds $\mathbf{1} / \boldsymbol{n}$, but upon further chain elongation the mesophase stability is reduced $(\mathbf{1} / \mathbf{1 4}>\mathbf{1 / 1 6})$, and for compounds $\mathbf{1} / \mathbf{1 8}$ and $\mathbf{1 / 2 2}$ the LC phases are removed again. So the major conclusion is that, though the non-centrosymmetric trigonal columnar organization can be retained, the 5-methyl group has a significant mesophase destabilizing effect. This disturbance can partly be compensated by optimizing the 2-alkyl chain length and, as described further below, by adding appropriate solvents, stabilizing the columns comprising the hydrogen bonding networks.

\subsection{Fluorescence properties}

UV investigation of dilute solution as well as thin films of compound 1/14 was performed (Fig. 2). In dilute solution $\left(10^{-6} \mathrm{~mol} \mathrm{~L}^{-1}\right.$ in THF) there is only one peak with a maximum at $302 \mathrm{~nm}$. In the thin film obtained after spin-coating from THF solution (thickness of about $1 \mu \mathrm{m}$ ) the absorption is blue shifted to $285 \mathrm{~nm}$ and simultaneously the peak is broadened (Fig. 2 left, dotted line) in 

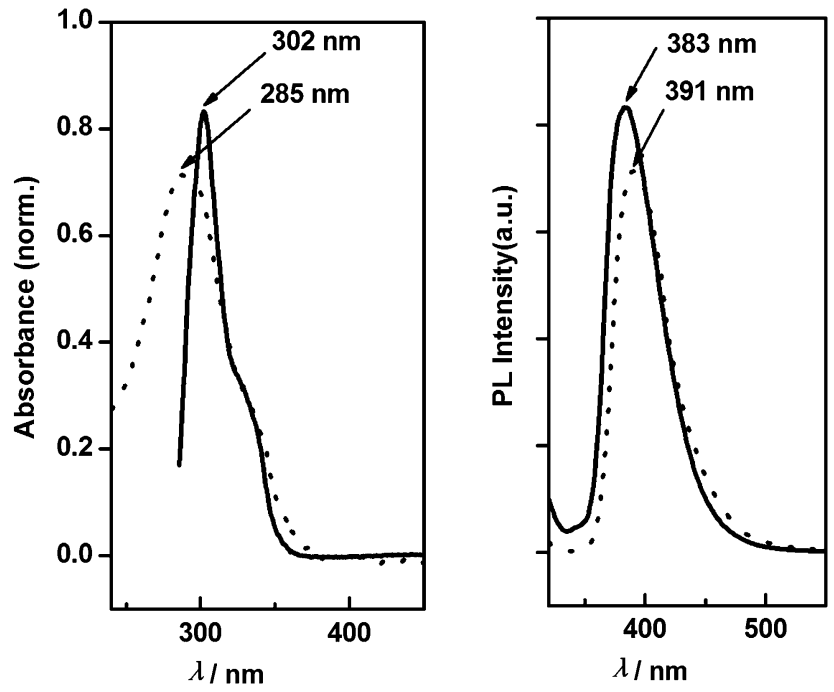

Fig. 2 UV-vis absorption (left) and PL spectra (right) of 1/14 in THF solution $\left(10^{-6} \mathrm{M}\right)$ (solid lines) and solid thin film (dot lines).

comparison to the solutions (solid line). These spectral changes can be ascribed to the formation of $\pi$-stacked aggregates with H-type parallel stacking mode. These optical features also support a self-organized $\pi$-stacked organization in the $\mathrm{Col}_{\text {hex }}$ phases (Fig. 1g). The photoluminescence (PL) spectrum of 1/14 in the thin film exhibits a broad and red-shifted emission peak at $391 \mathrm{~nm}$, while the solution displays structured emission with maxima at $383 \mathrm{~nm}$ (Fig. 2 right). Based on these properties the potential uses of this molecule could be as an active material in OFETs and a blue emitter in OLEDs. ${ }^{20}$

\subsection{Influence of solvents on the phase behavior}

Though only a few compounds show thermotropic mesomorphism as pure materials the mesophase stability of compounds 1/14 and 1/16 can be enhanced and LC phases can be induced for all other investigated homologues by addition of water, being incorporated into the hydrogen bonding networks of the glycerol groups, increasing the number of attractive intermolecular hydrogen bonding and thus stabilizing these networks (see Table 1). ${ }^{21}$ Therefore, compounds $\mathbf{1} / \mathbf{1 4}$ and 1/16 represent amphotropic LCs and the other compounds can be considered as mesogens forming solvent induced LC phases. ${ }^{22}$ All solventcontaining mesophases have spherulitic (Fig. 3a-c) or filament textures (Fig. 3d), very similar to the textures of the solvent-free samples, indicating columnar LC phases. As no change in the texture is observed in the whole temperature range of the solvent stabilized LC phases and also no discontinuity is observed in the contact region between $\mathbf{1} / \mathbf{1 4}$ or $\mathbf{1} / \mathbf{1 6}$ and water it is assumed that the added solvent does not modify the fundamental phase structure, but increases the mesophase stability by strengthening the hydrogen bonding networks. In all cases the highest clearing temperature of the mesophase is observed directly at the $\mathbf{1} / \boldsymbol{n}$-water interface and it decreases with decreasing water concentration (see Fig. 4b), indicating that the highest mesophase stability is obtained for the water saturated samples.
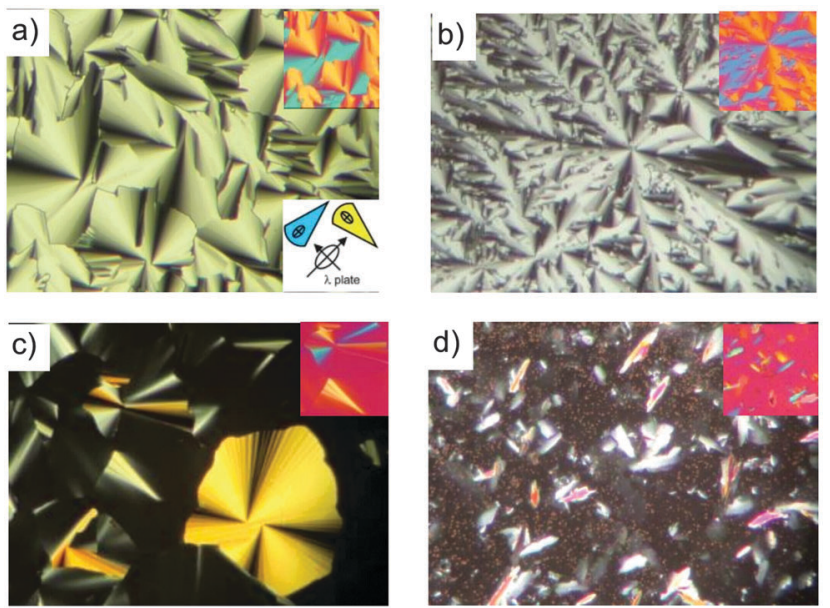

Fig. 3 Representative textures of columnar phases of compounds $1 / \boldsymbol{n}$ in water saturated samples as observed between crossed polarizers: (a) compound $1 / 6$ at $T=84^{\circ} \mathrm{C}$; (b) compound $1 / 12$ at $T=33^{\circ} \mathrm{C}$, (c) compound $1 / 14$ at $T=55^{\circ} \mathrm{C}$ and (d) compound $1 / 18$ at $T=51{ }^{\circ} \mathrm{C}$; the insets at the top right show sections of the textures with additional $\lambda$-retarder plates, indicating negative birefringence in all cases; the indicatrix orientation is shown in the bottom inset in (a).

The mesophase regions of compounds 1/14 and 1/16 are significantly expanded and become enantiotropic by addition of water, not only as a result of mesophase stabilization, but also due to the reduction of the melting temperatures by the added solvent. This leads to broad temperature ranges of a trigonal columnar LC phase down to ambient temperature. The LC phase of the water saturated compound 1/16 was investigated by XRD at $25{ }^{\circ} \mathrm{C}$ (Fig. 4). The diffraction pattern is characterized by a diffuse wide angle scattering at $d=$ $0.45 \mathrm{~nm}$ confirming the presence of an LC phase. The ratio of the reciprocal spacing in the small angle region is $1: 2$. Based on the observed textures a lamellar phase can be excluded and indexing as 10 and 20 reflections of a hexagonal lattice leads to $a_{\text {hex }}=2.95 \mathrm{~nm}$, which is slightly larger than that found for the pure 1/16 sample ( $\left.a_{\text {hex }}=2.77 \mathrm{~nm}\right)$. Nevertheless, the value is still in the range expected for a hexagonal honeycomb phase with the p3m1 lattice (see Fig. S4 and Table S1, ESI $\dagger$ ). This is in line with the incorporation of the solvent molecules into the columns formed by the hydrogen bonding networks between the glycerol units, thus leading to the swelling and a slight increase of the lattice parameter.

If the series of compounds $\mathbf{1} / \boldsymbol{n}$ is compared (see Table 1 ), it appears that the highest stability of the solvent induced LC phase is achieved for compounds with short chains and chain elongation decreases the mesophase stability. A possible reason could be restricted water uptake by the more hydrophobic long chain compounds. Moreover, the long alkyl chains can by themselves efficiently fill the space in the hexagonal cylinder cells thus leaving less space available for additional water molecules. This reduces the total number of possible hydrogen bondings and the honeycombs cannot be efficiently stabilized. The thermotropic as well as the solvent stabilized LC phases of compounds 1/14 and 1/16 represent $\mathrm{Col}_{\text {hex-3 }} / p 3 m 1$ phases, 

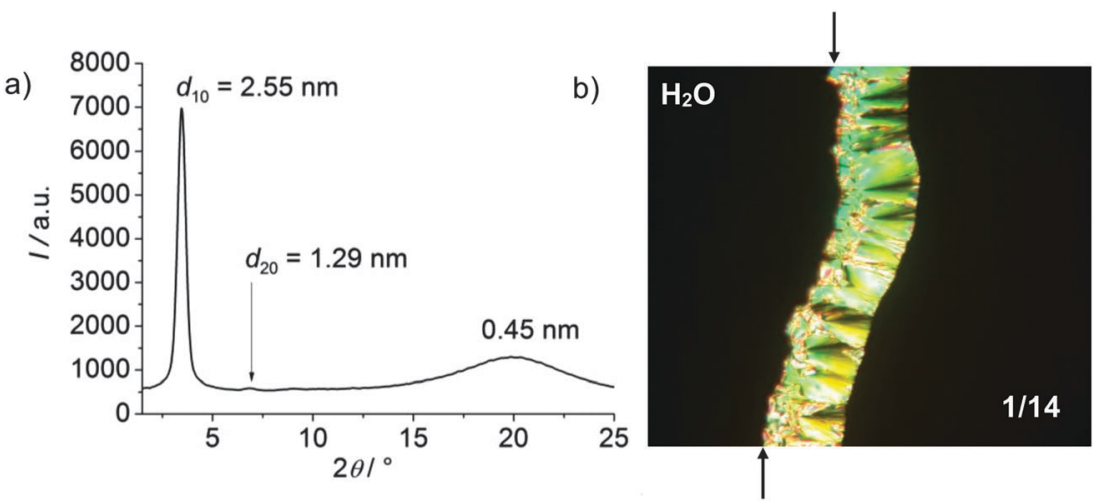

Fig. 4 (a) XRD pattern of the $\mathrm{Col}_{\text {nex }} / \mathrm{p} 3 \mathrm{~m} 1$ phase of the water saturated sample of compound $1 / 16$ at $T=25^{\circ} \mathrm{C}$; (b) contact region between water and $1 / 14$ as observed by POM during cooling at $T=66^{\circ} \mathrm{C}$; arrows indicate the interface between water and $1 / 14$

based on textural and XRD evidence. This is most likely also the case for the other homologues, as there is continuous development of the LC-Iso transition temperatures depending on the chain length and, in addition, all solvent-induced LC phases are optically negative as typical for honeycomb phases and indicated by investigation with a $\lambda$-retarder plate (see insets in Fig. 3). Nevertheless, there are some textural differences (see Fig. 3), which are most likely due to changes in the preferred alignment of the honeycombs depending on the chain length. Overall, it is most likely that all solvent induced LC phases indeed represent $\mathrm{Col}_{\text {hex } 3} / \mathrm{p} 3 m 1$ phases, though they cannot be stated with full certainty at present.

\section{Conclusions}

The bent-core bolaamphiphiles $\mathbf{1} / \boldsymbol{n}$ can self-assemble into monotropic 3-hexagon honeycomb type columnar liquid crystalline phases with non-centrosymmetric $p 3 m 1$ plane group symmetry if the alkyl chains in the bay position have a certain length $(n=14,16)$. In comparison with related compounds $2 / \boldsymbol{n}^{12}$ it is evident that the additional lateral methyl group at the apex reduces the mesophase stability, though the fundamental mode of self-assembly is not changed. This means that the non-centrosymmetric liquid crystalline phase is retained even in the presence of this substituent. This paves the way to new molecules with acceptor substituents at the apex for achieving nonlinear optically active LC materials. ${ }^{13}$ Moreover, water, as a typical protic solvent, was shown to stabilize, and widen or even might induce the non-centrosymmetric trigonal columnar phase ranges. This kind of trigonal columnar phase is extremely rare ${ }^{9,12,23}$ and most often hexasubstituted benzenes were previously used in attempts to design this kind of non-centrosymmetric LC phase. ${ }^{14}$ Especially lyotropic trigonal liquid crystalline phases were previously unknown. ${ }^{1}$ The approach presented here provides easy access to such LC phases with broad phase ranges including ambient temperature. Further structural modifications could potentially lead to liquid crystalline materials with significant second harmonic generation activity. ${ }^{13}$ Besides the non-centrosymmetric structure of the columnar phases the fluorescence properties of the investigated compounds are also of interest for potential applications.

\section{Experimental}

The detailed synthetic procedures, purification of the compounds together with the analytical data are reported in the ESI. $\dagger$ All cross-coupling reactions were conducted under argon and the glassware was oven-dried $\left(140{ }^{\circ} \mathrm{C}\right)$. Commercially available chemicals were used as received. ${ }^{1} \mathrm{H}$ NMR and ${ }^{13} \mathrm{C}$ NMR spectra were recorded in $\mathrm{CDCl}_{3}$ solution on a Bruker-DRX500 spectrometer with tetramethylsilane (TMS) as the internal standard. Elemental analysis was performed using an Elemental VARIO EL elemental analyzer. Column chromatography was performed using silica gel 60 (230-400 mesh) from Merck.

A Mettler heating stage (FP 82 HT) was used for polarizing optical microscopy (POM, Optiphot 2, Nikon) and DSCs were recorded using a DSC-7 calorimeter (Perkin Elmer) at $10 \mathrm{~K} \mathrm{~min}^{-1}$. X-ray diffraction patterns of partially aligned samples were recorded with a 2D detector (HI-STAR, Siemens) using a small droplet on a glass surface; Ni filtered and pin hole collimated $\mathrm{Cu}-\mathrm{K}_{\alpha}$ radiation was used and the beam was parallel to the surface. The exposure time was $60 \mathrm{~min}$. The sample-to-detector distance was $8.8 \mathrm{~cm}$ and $26.9 \mathrm{~cm}$ for the wide angle and small angle measurements, respectively. $2 \mathrm{D}$ frame integration was used to convert the patterns into one-dimensional intensity profiles and the evaluated peak positions were used for phase assignments. UV-vis absorption spectra were recorded on a UV-240 UV-visible spectrophotometer (Shimadzu, Japan). Fluorescence spectra were recorded using a Hitachi F-7000 fluorescence spectrometer (Hitachi, Japan). The spectral measurements were carried out at room temperature.

For investigation of the solvent-free samples the materials have been heated in an open sample to $>120{ }^{\circ} \mathrm{C}$ before investigation to remove all water traces, and exposure of the dry samples to humid air was avoided during investigation. Investigation of the effects of water on the samples was carried out between ordinary (non-treated) circular microscopy glass slides (Plano) by inspection of the contact region between $1 / n$ and water. In addition, compounds $1 / n$ were mixed with excess water and heated between glass slides to determine the LC-Iso transition temperatures of the water saturated samples. In order to avoid evaporation of water from these samples at elevated temperature, the sandwiched glass plates were placed in an optical 
transparent glass pan with a planar surface together with an excess of water around the sample.

\section{Acknowledgements}

This work was supported by the National Natural Science Foundation of China [no. 21364017 and 21274119], the Yunnan Natural Science Foundation (2013FA007) and Scholarship Award for Excellent Doctoral Student of Yunnan Province [no. ynuy201418]. M.P. and C.T. acknowledge the support by DFG (FOR 1145).

\section{References}

1 J. W. Goodby, J. P. Collings, T. Kato, C. Tschierske, H. F. Gleeson and P. Raynes, Handbook of Liquid Crystals, Wiley-VCH, Weinheim, Germany, 2nd edn, 2014.

2 M. Bremer, P. Kirsch, M. Klasen-Memmer and K. Tarumi, Angew. Chem., Int. Ed., 2013, 52, 8880-8896.

3 C. Tschierske, Angew. Chem., Int. Ed., 2013, 52, 8828-8878.

4 (a) C. Tschierske, Chem. Soc. Rev., 2007, 36, 1930-1970; (b) G. Ungar, C. Tschierske, V. Abetz, R. Holyst, M. A. Bates, F. Liu, M. Prehm, R. Kieffer, X. B. Zeng, M. Walker, B. Glettner and A. Zywocinski, Adv. Funct. Mater., 2011, 21, 1296-1323; (c) C. Tschierske, C. Nürnberger, H. Ebert, B. Glettner, M. Prehm, F. Liu, X. B. Zeng and G. Ungar, Interface Focus, 2012, 2, 669-680.

5 (a) M. Kölbel, T. Beyersdorff, X. H. Cheng, C. Tschierske, J. Kain and S. Diele, J. Am. Chem. Soc., 2001, 123, 6809-6818; (b) X. H. Cheng, M. Prehm, M. K. Das, J. Kain, U. Baumeister, S. Diele, D. Leine, A. Blume and C. Tschierske, J. Am. Chem. Soc., 2003, 125, 10977-10996.

6 (a) X. H. Cheng, X. Dong, G. H. Wei, M. Prehm and C. Tschierske, Angew. Chem., Int. Ed., 2009, 48, 8014-8017; (b) H. F. Gao, Y. F. Ye, L. Y. Kong, X. H. Cheng, M. Prehm, H. Ebert and C. Tschierske, Soft Matter, 2012, 8, 10921-10931; (c) X. H. Cheng, H. F. Gao, X. P. Tan, X. Y. Yang, M. Prehm, H. Ebert and C. Tschierske, Chem. Sci., 2013, 4, 3317-3331; (d) W. Bu, H. F. Gao, X. P. Tan, X. Dong, X. H. Cheng, M. Prehm and T. Tschierske, Chem. Commun., 2013, 49, 1756-1758.

7 R. Kieffer, M. Prehm, B. Glettner, K. Pelz, U. Baumeister, F. Liu, X. B. Zeng, G. Ungar and C. Tschierske, Chem. Commun., 2008, 3861-3863.

8 (a) C. Tschierske, Top. Curr. Chem., 2012, 318, 1-108; (b) B. Glettner, F. Liu, X. B. Zeng, M. Prehm, U. Baumeister, M. A. Bates, M. Walker, P. Boesecke, G. Ungar and C. Tschierske, Angew. Chem., Int. Ed., 2008, 47, 9063-9066; (c) F. Liu, R. Kieffer, X. B. Zeng, K. Pelz, M. Prehm, G. Ungar and C. Tschierske, Nat. Commun., 2012, 3, 1104-1110.

9 X. B. Zeng, R. Kieffer, B. Glettner, C. Nürnberger, F. Liu, K. Pelz, M. Prehm, U. Baumeister, H. Hahn, H. Lang, G. A. Gehring, C. H. M. Weber, J. K. Hobbs, C. Tschierske and G. Ungar, Science, 2011, 331, 1302-1306.

10 (a) D. R. Link, G. Natale, R. Shao, J. E. Maclennan, N. A. Clark, E. Körblova and D. M. Walba, Science, 1997, 278, 1924-1927; (b) R. A. Reddy and C. Tschierske, J. Mater.
Chem., 2006, 16, 907-961; (c) H. Takezoe and Y. Takanishi, Jpn. J. Appl. Phys., 2006, 45, 597-625; (d) A. Eremin and A. Jakli, Soft Matter, 2013, 9, 615-637.

11 K. Geese, M. Prehm and C. Tschierske, Chem. Commun., 2014, 50, 9903-9906.

12 B. Glettner, F. Liu, X. B. Zeng, M. Prehm, U. Baumeister, G. Ungar and C. Tschierske, Angew. Chem., Int. Ed., 2008, 47, 6080-6083.

13 S. R. Marder, Chem. Commun., 2006, 131-134.

14 (a) G. Hennrich, A. Omenat, I. Asselberghs, S. Foerier, K. Clays, T. Verbiest and J. L. Serrano, Angew. Chem., Int. Ed., 2006, 45, 4203-4206; (b) G. Hennrich, P. D. Ortiz, E. Cavero, R. E. Hanes and J. L. Serrano, Eur. J. Org. Chem., 2008, 4575-4579; (c) L. de Vega, S. van Cleuvenbergen, G. Depotter, E. M. García-Frutos, B. GómezLor, A. Omenat, R. M. Tejedor, J. L. Serrano, G. Hennrich and K. Clays, J. Org. Chem., 2012, 77, 10891-10896; (d) G. Argouarch, R. Veillard, T. Roisnel, A. Amar, H. Meghezzi, A. Boucekkine, V. Hugues, O. Mongin, M. Blanchard-Desce and F. Paul, Chem. - Eur. J., 2012, 18, 11811-11827; (e) S. H. Lee, J. R. Park, M. Y. Jeong, H. M. Kim, S. Li, J. Song, S. Ham, S. J. Jeon and B. R. Cho, ChemPhysChem, 2006, 7, 206-212.

15 (a) A. Burger, E. L. Wilson, C. O. Brindley and F. Bernheim, J. Am. Chem. Soc., 1945, 67, 1416-1419; (b) K. Omura, J. Org. Chem., 1984, 49, 3046-3050.

16 J. Vollmeyer, U. Baumeister and S. Höger, Beilstein J. Org. Chem., 2014, 10, 910-920.

17 (a) B. Glettner, F. Liu, X. B. Zeng, M. Prehm, U. Baumeister, M. Walker, M. A. Bates, P. Boesecke, G. Ungar and C. Tschierske, Angew. Chem., Int. Ed., 2008, 120, 9203-9206; (b) X. P. Tan, L. Y. Kong, H. Dai, X. H. Cheng, F. Liu and C. Tschierske, Chem. - Eur. J., 2013, 19, 16303-16313.

18 (a) K. Sonogashira, Y. Tohda and N. Hagihara, Tetrahedron Lett., 1975, 16, 4467-4470; (b) J. L. Wang, J. Yan, Z. M. Tang, Q. Xiao, Y. G. Ma and J. Pei, J. Am. Chem. Soc., 2008, 130, 9952-9962; (c) J. L. Wang, Z. M. Tang, Q. Xiao, Q. F. Zhou, Y. G. Ma and J. Pei, Org. Lett., 2008, 10, 17-20.

19 R. Sterzycki, Synthesis, 1979, 724-725.

20 Though the thermal and photochemical stability was not investigated in detail, the compounds gave identical DSC curves in several heating cooling cycles up to $150{ }^{\circ} \mathrm{C}$ and no bleaching was observed during UV and PL investigations, indicating reasonable stability of these materials.

21 Depending on the molecular structure, especially the chemical structure of the polar head group, the used solvent, and the size and polarity of the lipophilic molecular segments, added solvents can have a mesophase stabilizing or mesophase destabilizing effect, as discussed in ref. 21; for more recent examples, see: T. Ichikawa, M. Yoshio, S. Taguchi, J. Kagimoto, H. Ohno and T. Kato, Chem. Sci., 2012, 3, 2001-2008; E. C. Wijaya, T. L. Greaves and C. J. Drummond, Faraday Discuss., 2013, 167, 191-215.

22 (a) C. Tschierske, Prog. Polym. Sci., 1996, 21, 775-852; (b) C. Tschierske, Curr. Opin. Colloid Interface Sci., 2002, 7, 355-370.

23 T. N. Y. Hoang, D. Pociecha, M. Salamonczyk, E. Gorecka and R. Deschenaux, Soft Matter, 2011, 7, 4948-4953. 